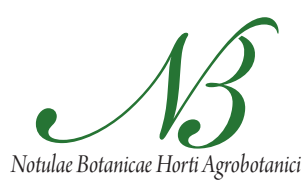

Cluj-Napoca

\title{
In vitro Regeneration of Dalbergia sissoo Roxb. and the Potential for Genetic Transformation
}

\author{
Hafiz Mamoon REHMAN ${ }^{1}$, Iqrar Ahmad RANA ${ }^{* *}$, Siddra IJAZ', Ghulam \\ MUSTAFA', Faiz Ahmad JOYIA ${ }^{1}$, Iqrar Ahmad KHAN'1', Paula M. PIJUT ${ }^{2}$ \\ ${ }^{1}$ Center of Agricultural Biochemistry and Biotechnology, University of Agriculture, 38040, \\ Faisalabad,Pakistan; iqrar_rana@uaf.edu.pk (*corresponding author) \\ ${ }^{2}$ USDA Forest Service, Northern Research Station, Hardwood Tree Improvement and Regeneration \\ Center, 715 West State Street, West Lafayette, Indiana 47907, USA
}

\begin{abstract}
Dalbergia sissoo Roxb. ex DC. (Sissoo) is a native forest tree species in Pakistan. Many ecological and economical uses are associated with this premier timber species, but dieback disease is of major concern. The objective of this study was to develop a protocol for in vitro regeneration of Sissoo that could serve as target material for genetic transformation, in order to improve this species. Callus formation and plantlet regeneration was achieved by culturing cotyledons, immature seeds, and mature embryos on a modified Murashige and Skoog (1962) (MS) medium supplemented with plant growth regulators. Callus induction medium containing $2.71 \mu \mathrm{M}$ 2, 4-dichlorophenoxyacetic acid (2,4-D) and $0.93 \mu \mathrm{M}$ kinetin produced better callus on all explants tested compared to other treatments, such as $8.88 \mu \mathrm{M}$ 6-benzylaminopurine (BA) and $2.69 \mu \mathrm{M} \alpha$-naphthalene acetic acid (NAA), or 2.71 $\mu \mathrm{M} 2$, 4-D and $2.69 \mu \mathrm{M}$ NAA. Shoot regeneration was best on MS medium containing 1.4 $\mu \mathrm{M}$ NAA and $8.88 \mu \mathrm{M}$ BA compared to other treatments, such as $1.4 \mu \mathrm{M}$ NAA and $9.9 \mu \mathrm{M}$ kinetin, or $2.86 \mu \mathrm{M}$ indole-3-acetic acid and $8.88 \mu \mathrm{M}$ BA. Murashige and Skoog medium containing 1.4 NAA $\mu \mathrm{M}$ and $8.88 \mu \mathrm{M}$ BA was better in general for regeneration regardless of callus induction medium and the type of explant used. Rooting was best on half-strength MS medium with $7.35 \mu \mathrm{M}$ indole-3-butyric acid. Regenerated plantlets were acclimatized for plantation in the field. Preliminary genetic transformation potential of D. sissoo was evaluated by particle bombardment of callus explants with a $p U b i G u s$ vector. The bombarded tissue showed transient Gus activity 1week after bombardment. Transformation of this woody tree is possible provided excellent regeneration protocols. The best combination for regeneration explained in this study is one of such protocols.
\end{abstract}

Keywords: Dalbergia sissoo, genetic transformation, in vitro regeneration, Sissoo

\section{Introduction}

Dalbergia sissoo Roxb. ex DC. (Sissoo; Fabaceae) is a native forest tree species in Pakistan and the neighboring countries of Nepal, India, and Bhutan. Many ecological and economical uses are associated with this premier timber species, such as nitrogen-fixation, shade, shelter, fodder, wood for fuel and furniture, and the sawdust is used for the removal of nickel ions and heavy metals from industrial waste water. Mortality of Sissoo trees has been associated with dieback disease and it is a critical threat to this species (Appanah et al., 2000). Dieback disease has caused widespread mortality of D. sissoo throughout South Asia, and trees of all ages from saplings to mature trees are affected. Many efforts are being made to overcome this disease, and the causal organism associated with dieback disease was found to be Fusarium solani (Bakshi and Singh, 1967; Shakya and Lakhey, 2007). Shukla (2008) carried out resistance screening of seeds from a number of provenances, and pathogenicity of $F$. solani f.sp. dalbergia isolated from roots and oozing pitch of dying trees was also evaluated.
Genetic transformation and in vitro regeneration has become an indispensable means to engineer plant genomes with desirable traits, and a tool in functional genomics research to manipulate organisms at the cellular level. In trees, high background polymorphisms, long regeneration times to maturity, and difficulty in breeding programs makes it difficult to produce isogenic lines for use as large experimental units. For establishing direct genetic linkages between genes and phenotypes, one way is to engineer the genomes at the molecular level. Trees will always be attacked by a range of organisms that cause decline. Genetic transformation may be a solution to overcome these critical forestry situations, such as dieback of Sissoo, in order to conserve the trees in all parts of the world. But, in vitro regeneration protocols must be established that can be used to overcome this hurdle and manipulate the tree genome.

Several reports have been published on in vitro propagation of D. sissoo using nodal, hypocotyl, cotyledon, and zygotic embryo explants; however none of these explants 
have been utilized for genetic transformation studies. $\mathrm{Su}$ wal et al. (1988) reported multiple shoot induction from the nodal region of D. sissoo cotyledons cultured on $\mathrm{Mu}$ rashige and Skoog (1962) (MS) medium supplemented with 6-benzylaminopurine (BA) and $\alpha$-naphthalene acetic acid (NAA), and shoots were rooted in non-sterile sand beds. Sharma and Chandra (1988) produced shoots from Sissoo hypocotyl explants cultured on MS medium supplemented with BA plus indole-3-acetic acid (IAA), indole3 -butyric acid (IBA), or NAA, and shoots were rooted in MS medium with IBA, NAA, IAA, or IBA plus NAA. Kumar et al. (1991) reported regeneration of shoots from cell suspension-derived calli of cambial origin on MS medium containing only BA, with rooting achieved in medium containing IAA, IBA, and NAA. Nodal segments obtained from coppiced shoots of D. sissoo produced shoots on MS medium containing BA and $\beta$-naphthoxy acetic acid, and rooting was achieved in a multi-step process using IBA, liquid medium, and activated charcoal (Gulati and Jaiwal, 1996). Das et al. (1997) obtained somatic embryogenesis from 40-day-old semi-mature zygotic embryos cultured on MS medium with kinetin and 2, 4-dichlorophenoxyacetic acid (2,4-D), and the developmental stages were analyzed by light and scanning electron microscopy. Cotyledonary nodes from axenic seedlings were used for in vitro shoot proliferation of $D$. sissoo on MS medium containing either BA, kinetin, isopentenyladenine, or thidiazuron, and rooting achieved on half-strength MS medium containing IAA, IBA, and indole-3-propionic acid (Pradhan et al., 1998). Shoot organogenesis and complete plantlet regeneration from cell suspension cultures of D. sissoo, initiated from hypocotyl explants, was achieved using MS medium with various combinations of $\mathrm{BA}$ and NAA (Pattnaik et al., 2000). Adventitious shoot organogenesis from semi-mature and mature cotyledons was achieved on MS medium with BA and NAA, and rooting of shoots was accomplished using half-strength MS medium containing IBA (Singh et al., 2002). Micropropagation from nodal explants of $D$. sissoo was achieved on MS medium with BA, IAA, kinetin, or NAA (Ali et al., 2012; Joshi et al., 2003). Somatic embryogenesis has also been achieved with $D$. sissoo semi-mature zygotic and cotyledon explants cultured on MS medium with 2,4-D and kinetin (Chand and Singh, 2005; Singh and Chand, 2003). There are also many conventional methods of propagation of $D$. sissoo using seeds, but germination was very low and cannot produce disease-free plants. Therefore, development of a genetic transformation and regeneration system would be an efficient way to obtain mass multiplication of disease-free transgenic plants with improved traits. The objective of this study was to develop a protocol for the in vitro regeneration of D. sissoo plants that could serve as target material for genetic transformation. We report on the stable expression of the Gus reporter gene in Sissoo by using calli from mature embryos.

\section{Materials and methods}

\section{Plant material}

Immature and mature (green to brown in color) pods of Sissoo with healthy seeds were collected in early March 2010 from the upper and lower branches of five different mature D. sissoo trees growing at the University of Agriculture Faisalabad, Pakistan. To the best of our knowledge, these trees were wild genotypes to the Faisalabad area, and thus the potential value as clonal material was unknown. Pods were placed in plastic bags with wet paper towels and stored at $4^{\circ} \mathrm{C}$ until used. Pods were rinsed under running water for $25 \mathrm{~min}$ to remove debris, and then the pods were washed with Tween 20 (10 drops per $100 \mathrm{ml}$ water) for 5 min with gentle shaking. Pods were then treated with a $3 \%$ (v/v) antiseptic solution of Dettol ( $4.8 \%$ chloroxylenol as active ingredient) for $15 \mathrm{~min}$, followed by rinsing four to five times with distilled water. Pods were then rinsed in $70 \%(\mathrm{v} / \mathrm{v})$ ethanol for 1 to 2 min under aseptic conditions, treated with $0.01 \mathrm{M}$ hydrochloric acid for $4 \mathrm{~min}$, and then rinsed with sterile, double-distilled water three times. These surface disinfested pods were then used to obtain three different types of explants. Green pods were used for immature seeds, and mature pods were used to obtain mature embryos and cotyledons.

\section{Culture medium and conditions}

Murashige and Skoog (1962) medium with different auxin and cytokinin ratios were screened for callus induction and regeneration from cotyledons, immature seeds, and mature embryos of Sissoo. The callus induction media evaluated were those of Sharma and Chandra (1988) and Chand and Singh (2004, 2005). Unless stated otherwise, MS basal salt medium (M524, PhytoTechnology Laboratories, USA) contained MS vitamins (M533, PhytoTechnology Laboratories, USA), 3\% (v/v) sucrose, and $0.266 \%$ (v/v) Phytagel". The $\mathrm{pH}$ of all media was adjusted to 5.76 \pm 0.02 using $0.1 \mathrm{~N} \mathrm{HCl}$ and $\mathrm{NaOH}$ before autoclaving at $121^{\circ} \mathrm{C}$ for $20 \mathrm{~min}$. Culture medium was sterilized by autoclaving at temperature of $121^{\circ} \mathrm{C}(15 \mathrm{psi})$ for $20 \mathrm{~min}$. All cultures were incubated in a growth room under $16 \mathrm{~h}$ light at 2500 lux light intensity $\left(34 \mu \mathrm{mol} \mathrm{m} \mathrm{m}^{-2} \mathrm{~s}^{-1}\right)$ provided by cool-white fluorescent tubes at $26 \pm 2^{\circ} \mathrm{C}$.

\section{Callus Induction Medium (CIM)}

For callus induction, seven to eight excised cotyledons (after germination on half-strength MS medium), immature seeds, and mature embryos were cultured in $100 \times 15$ $\mathrm{mm}$ Petri dishes containing 25-30 ml culture medium. For callus induction, basal MS medium with three different combinations of auxin and cytokinin were used: 1) CIM1; $2.71 \mu \mathrm{M} 2$ 2, 4-D and $0.93 \mu \mathrm{M}$ kinetin, 2) CIM2; $8.88 \mu \mathrm{M}$ BA and $2.69 \mu \mathrm{M}$ NAA, or 3) CIM3; $2.71 \mu \mathrm{M}$ 2,4-D and $2.69 \mu \mathrm{M}$ NAA. Callus induction was initiated in the dark for 15 to 20 days of culture, and then transferred to a 16 $\mathrm{h}$ photoperiod at $26 \pm 2^{\circ} \mathrm{C}$ with light intensity of 2500 lux 
142

$\left(34 \mu \mathrm{mol} \mathrm{m}^{-2} \mathrm{~s}^{-1}\right)$ provided by cool-white fluorescent tubes. All treatments were replicated three times. Visual rating of callus induction was based on the following scale: $0=$ no callus; $1=$ callus induction, but no de-differentiation; $2=$ callus induction and small amount of de-differentiation; $3=$ callus induction and complete de-differentiation; $4=$ large callus induction and complete differentiation; and $5=$ large callus induction and embryogenesis. The occurrence and type of callus for each type of explant was recorded daily.

\section{Shoot Regeneration Medium (RM)}

Following 15 to $20 \mathrm{~d}$ of callus induction, all surviving callus were transferred to basal MS medium with three different combinations of auxin and cytokinin for indirect adventitious shoot regeneration: 1) RM1; $1.4 \mu \mathrm{M}$ NAA and $8.88 \mu \mathrm{M} \mathrm{BA}, 2) \mathrm{RM} 2 ; 1.4 \mu \mathrm{M}$ NAA and $9.9 \mu \mathrm{M}$ kinetin, or 3) RM3; $2.86 \mu \mathrm{M}$ IAA and $8.88 \mu \mathrm{M}$ BA. Callus explants were transferred to fresh media treatments $(18 \times 2$ $\mathrm{cm}$ test tubes) every $15 \mathrm{~d}$ until shoots appeared or growth ceased. All treatments were replicated three times. After 4 weeks on regeneration medium, callus with shoots and without shoots were recorded, and the percentage of shoots regenerated was calculated based on the initial number of explants tested. All cultures for shoot regeneration were maintained under continuous $24 \mathrm{~h}$ light intensity of 2500 lux $\left(34 \mu \mathrm{mol} \mathrm{m} \mathrm{m}^{-2} \mathrm{~s}^{-1}\right)$ provided by cool-white fluorescent tubes at $25 \pm 2^{\circ} \mathrm{C}$.

\section{Root induction}

When shoots reached $3 \mathrm{~cm}$ in length, 20 shoots each were excised from the callus clusters and individually transferred to half-strength MS medium with $7.35 \mu \mathrm{M}$ IBA or without IBA, and placed under lighted conditions. The experiment was repeated thrice. Once rooted, plantlets were transferred to a 2:1 peat:moss mixture in pots and placed in a humidifying chamber set to provide a $16 \mathrm{~h}$ photoperiod at $26^{\circ} \mathrm{C}$. Plantlets were watered with tap water once per week, gradually acclimatized to lower humidity, and after 2 to 3 months were transferred to the greenhouse.

\section{Micro-projectile bombardment}

Callus was induced from mature embryos cultured on CIM1. Cultured embryos were kept in the dark for $15 \mathrm{~d}$ for callus initiation. Callus was placed in the center of petri plates under aseptic conditions in order to make them amenable for gene transformation. The gene gun was properly sterilized to avoid contamination. Gene delivery into the callus was carried out by particle bombardment using the BIORAD PDS-1000/He Particle Gun (BioRad, Munich, Germany). Fifteen-day-old callus of D. sissoo were cultured on CIM1 prior to bombardment. DNA coating of gold particles and bombardment of Sissoo callus was based on the protocol by Becker et al. (1994) with wheat. Gold particles $(0.2 \mathrm{mg})$ having an average size between 0.4 and $0.8 \mu \mathrm{m}$ were coated with $5 \mu \mathrm{g}$ of the plasmid DNA of the pUbiGus vector (Fig. 1) for transient transformation. Particle bombardment was carried out with Helium gas at 1350 psi under a partial vacuum of $27 \mathrm{mmHg}$ according to Rana et al. (2012) and Brettschneider et al. (1997). The bombarded callus remained on CIM1 for $8 \mathrm{~d}$ until used for the histochemical GUS assay.

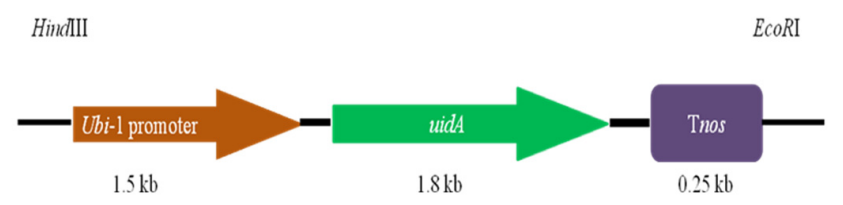

Fig. 1. Expression Cassette: pUbiGus vector showing ubil promoter, glucuronidase (uid $A$ ) and Tnos terminator gene regions

\section{Histochemical GUS assay}

In order to check the efficiency of the biolistic bombardment, related factors of transformation, as well as the proper functioning of the pUbiGus in callus of Sissoo, the GUS assay was performed. GUS activity was determined histochemically (Jefferson et al., 1987) $8 \mathrm{~d}$ after bombardment. Callus was incubated for $12-16 \mathrm{~h}$ at $37^{\circ} \mathrm{C}$ in staining buffer containing X-Gluc (5-bromo-4-chloro-3-indolyl$\beta$-D-glucuronic acid), sodium buffer ( $\mathrm{pH} 7.0$ ), and $0.5 \%$ Triton X-100 as a substrate. GUS activity was visually observed and photographed.

\section{Statistical analysis}

All experiments were conducted as a completely randomized design with three replications per treatment. The data were analyzed by ANOVA and averages compared by least significant differences (Steel and Torrie, 1980).

\section{Results}

\section{Callus Induction Medium (CIM)}

Callus induction is influenced by a number of factors in woody and cultivated field crop plants. Analysis of variance (Tab. 1a) revealed the significant variation among CIM and explants. Variations among explants as well as among CIM were highly significant. Interactions among the Explants $\times$ CIM were non-significant. Tab. $1 \mathrm{~b}$ shows the comparison of the mean values of explants for callus induction on the three CIM. The mean values for immature cotyledons, immature seeds, and mature embryos were $2.49,2.71$, and 3.06 , respectively. The highest callus induction rate was found with mature embryos. The lowest callus induction was found with immature cotyledons. By comparing the different mean values of the explants on different CIM, results showed that mature embryos were the best explants for callus induction, versus immature cotyledons and immature seeds. Tab. $1 \mathrm{~b}$ also shows the comparison of the mean values of CIM. The mean values for CIM1, CIM2, and CIM3 were 3.39, 2.89, and 1.97, respectively. It was found that CIM1 $(2.71 \mu \mathrm{M} 2,4-\mathrm{D}$ plus $0.93 \mu \mathrm{M}$ kinetin) gave the highest callus rates for all ex- 
Tab. 1a. Analysis of variance for callus induction from Dalbergia sissoo explants

\begin{tabular}{ccccc}
\hline Source of variation & Degrees of freedom & Sum of squares & Mean squares & F-value \\
\hline Explants & 2 & 1.5024 & 0.75120 & $26.26^{* *}$ \\
CIM & 2 & 9.3057 & 4.65287 & $162.62^{* *}$ \\
Explants $\times$ CIM & 4 & 0.1593 & 0.03981 & $1.39^{\text {NS }}$ \\
Error & 18 & 0.5150 & 0.02861 & \\
Total & 26 & 11.4824 & & \\
\hline
\end{tabular}

NS = Non-significant $(p>0.05) ;{ }^{* *}=$ Highly significant $(p<0.01)$

Tab. 1b. Mean values for callus induction from three explant types of Dalbergia sissoo

\begin{tabular}{ccccc}
\hline \multirow{2}{*}{ Treatment } & \multicolumn{3}{c}{ Explants } & \multirow{2}{*}{ Mean } \\
\cline { 2 - 4 } & Immature cotyledons & Immature seeds & Mature Embryos & $3.39 \pm 0.12 \mathrm{~A}$ \\
\hline CM1 & $2.98 \pm 0.16$ & $3.45 \pm 0.08$ & $3.73 \pm 0.04$ & $2.89 \pm 0.09 \mathrm{~B}$ \\
CM2 & $2.70 \pm 0.05$ & $2.77 \pm 0.04$ & $3.22 \pm 0.15$ & $1.97 \pm 0.08 \mathrm{C}$ \\
CM3 & $1.78 \pm 0.12$ & $1.90 \pm 0.08$ & $2.23 \pm 0.07$ & \\
Mean & $2.49 \pm 0.19 \mathrm{C}$ & $2.71 \pm 0.23 \mathrm{~B}$ & $3.06 \pm 0.23 \mathrm{~A}$ & \\
\hline
\end{tabular}

Means with the same letter in a row or in a column were not statistically significant $(p>0.05)$

CIM1: $2.71 \mu \mathrm{M} 2$, 4-D and $0.93 \mu \mathrm{M}$ kinetin, CIM2: $8.88 \mu \mathrm{M}$ BA and 2.69 $\mu \mathrm{M}$ NAA, or CIM3: 2.71 $\mu \mathrm{M} 2,4-\mathrm{D}$ and 2.69 $\mu \mathrm{M}$ NAA

plants with a mean value of $3.39 \pm 0.12$. CIM3 $(2.71 \mu \mathrm{M}$ 2 , 4-D plus $2.69 \mu \mathrm{M}$ NAA) gave the lowest yield of callus for all explants tested. Results presented in Tab. $1 \mathrm{~b}$ showed a highly significant difference among the various explants and media treatments on callus induction, while the interaction of the various explants and induction media was non- significant. All explants tested for callus induction had a significant effect on callus rate, and were different from each other (Fig. 2). CIM1 and mature embryo explants responded the best overall for callus induction (3.73 \pm 0.04 ) with respect to color, structure, organogenesis, friable $v$ s. non-friable, and quantity (Fig. 3).

\section{Shoot Regeneration Medium (RM)}

The analysis of variance for shoot regeneration showed that there was highly significant variation among explants

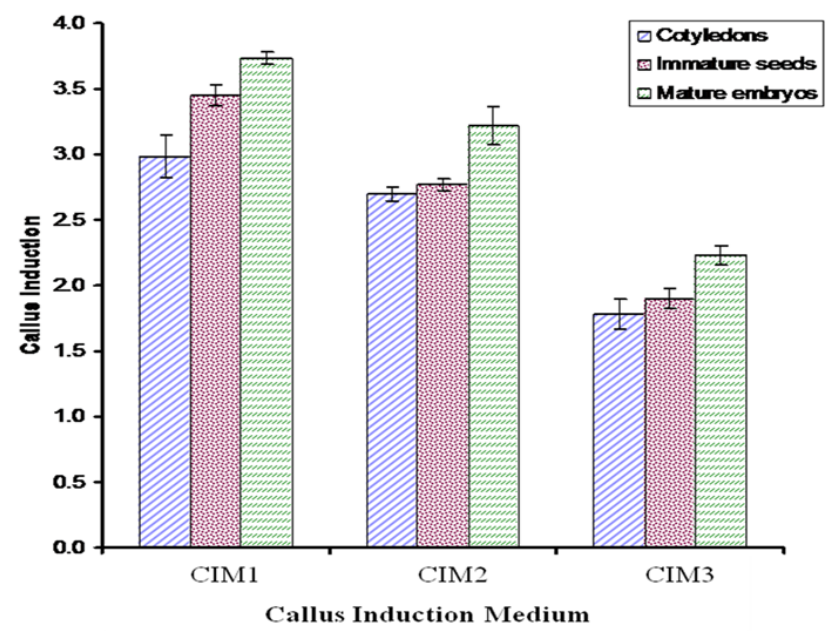

Fig. 2. The rate of callus induction on cotyledons, immature seeds, and mature embryos on three different callus induction media (CIM). CIM1: $2.71 \mu \mathrm{M}$ 2, 4-D and $0.93 \mu \mathrm{M}$ kinetin, CIM2: $8.88 \mu \mathrm{M}$ BA and 2.69 $\mu \mathrm{M}$ NAA, or CIM3: $2.71 \mu \mathrm{M} 2,4-$ $\mathrm{D}$ and $2.69 \mu \mathrm{M}$ NAA and RM, and the interaction (Tab. 2a). Tab. $2 b$ shows the comparison of the mean values of explants for shoot regeneration on the three RM. The mean values for immature cotyledons, immature seeds, and mature embryos on shoot induction were $0.77,0.82$, and 1.54 , respectively. Mature embryo callus produced the greatest shoot induction. The least responsive for shoot induction was found with immature cotyledon callus. Tab. $2 \mathrm{~b}$ also shows the comparison of the mean values for RM. The mean values for RM1, RM2, and RM3 were 1.87, 0.86, and 0.39, respectively. RM1 $(1.4 \mu \mathrm{M}$ NAA and $8.88 \mu \mathrm{M} \mathrm{BA})$ was found to be the best medium for shoot induction for all explants with a mean value of $1.87 \pm 0.14$. The least response for shoot induction was observed on RM3 for all explants tested. Shoot induction on RM2 $(1.4 \mu \mathrm{M}$ NAA and $9.9 \mu \mathrm{M}$ kinetin) was higher than RM3 $(2.86 \mu \mathrm{MIAA}$ and $8.88 \mu \mathrm{M} \mathrm{BA})$, but lower than RM1. RM1 and mature embryo callus responded the best overall with 2.4 shoots regenerated per explant (Fig. 5).

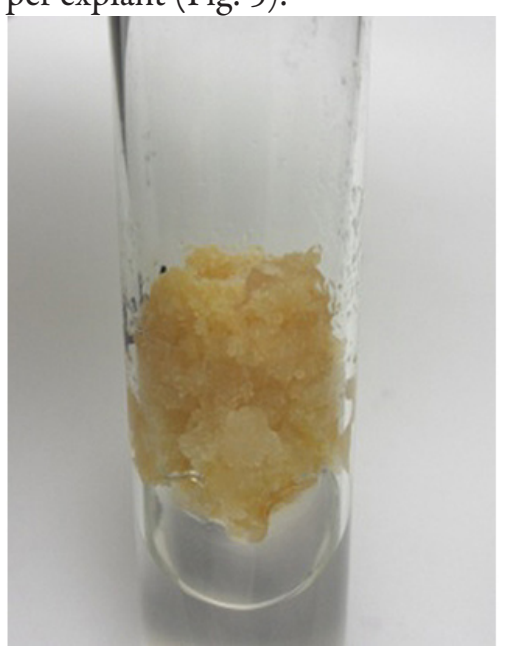

Fig. 3. Callus induction on mature embryo explant cultured on CIM1 (2.71 $\mu \mathrm{M} 2$, 4-D and $0.93 \mu \mathrm{M}$ kinetin) 
144

Tab. 2a. Analysis of variance for shoot induction from Dalbergia sissoo explants

\begin{tabular}{ccccc}
\hline Source of variation & Degrees of freedom & Sum of squares & Mean squares & F-value \\
\hline Explant & 2 & 3.3613 & 1.68065 & $82.88^{* *}$ \\
RM & 2 & 10.1891 & 5.09454 & $251.24^{* *}$ \\
Explant $\times$ RM & 4 & 0.3098 & 0.07745 & $3.82^{*}$ \\
Error & 18 & 0.3650 & 0.02028 & \\
Total & 26 & 14.2252 & & \\
\hline
\end{tabular}

${ }^{*}=$ Significant $(p<0.05) ;{ }^{* *}=$ Highly significant $(p<0.01)$

Tab. 2b. Mean values for shoot induction from three explant types of Dalbergia sissoo

\begin{tabular}{ccccc}
\hline \multirow{2}{*}{ Treatment } & \multicolumn{3}{c}{ Explants } & \multirow{2}{*}{ Mean } \\
\cline { 2 - 4 } & Immature cotyledons & Immature seeds & Mature Embryos & $1.87 \pm 0.14 \mathrm{~A}$ \\
\hline RM1 & $1.48 \pm 0.12 \mathrm{~b}$ & $1.72 \pm 0.07 \mathrm{~b}$ & $2.40 \pm 0.00 \mathrm{a}$ & $0.86 \pm 0.17 \mathrm{~B}$ \\
RM2 & $0.57 \pm 0.14 \mathrm{c}$ & $0.52 \pm 0.10 \mathrm{c}$ & $1.50 \pm 0.00 \mathrm{~b}$ & $0.39 \pm 0.09 \mathrm{C}$ \\
RM3 & $0.25 \pm 0.08 \mathrm{~d}$ & $0.22 \pm 0.07 \mathrm{~d}$ & $0.72 \pm 0.03 \mathrm{c}$ & \\
Mean & $0.77 \pm 0.19 \mathrm{~B}$ & $0.82 \pm 0.23 \mathrm{~B}$ & $1.54 \pm 0.24 \mathrm{~A}$ & \\
\hline
\end{tabular}

Means with the same letter in a row or in a column were not statistically significant $(p>0.05)$

Lowercase letters represent comparison among interaction means and uppercase letters were used for overall mean

RM1: $1.4 \mu \mathrm{M}$ NAA and $8.88 \mu \mathrm{M}$ BA, RM2: $1.4 \mu \mathrm{M}$ NAA and $9.9 \mu \mathrm{M}$ kinetin, or RM3: $2.86 \mu \mathrm{M}$ IAA and $8.88 \mu \mathrm{M}$ BA

\section{Root Induction}

Root induction was only observed on half-strength MS medium with IBA (Fig. 6). Root induction was observed between 15-20 d after culture on root induction medium. Root initiation started with the formation of callus at the base of the shoots, and root numbers varied between one to three roots per shoot with a mean root length of $2.5 \mathrm{~cm}$. Rooted plantlets were successfully acclimatized and maintained under greenhouse conditions for future use.

\section{Micro-Projectile Bombardment}

Genetic transformation of 3 weeks old callus derived from mature embryos was achieved using the biolistic

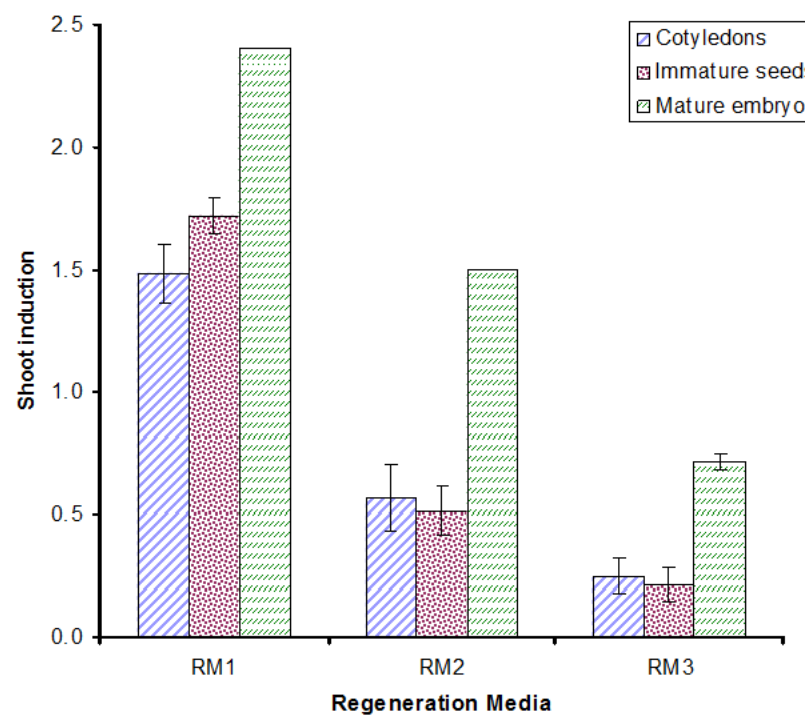

Fig. 4. The rate of shoot regeneration from cotyledons, immature seeds, and mature embryos on three different shoot regeneration media (RM). RM1: $1.4 \mu \mathrm{M}$ NAA and $8.88 \mu \mathrm{M}$ BA, RM2: $1.4 \mu \mathrm{M}$ NAA and $9.9 \mu \mathrm{M}$ kinetin, or RM3: $2.86 \mu \mathrm{M}$ IAA and $8.88 \mu \mathrm{MBA}$ gene gun. The uid $A$ gene under the control of an ubiquitin promoter and nos terminator was successfully bombarded into the tissue, and the histochemical assay of the transformed callus was conducted 1 week after bombardment. The bombarded callus showed blue spots (Fig. 9).

\section{Discussion}

In this study, callus induction from immature cotyledons, immature seeds, and mature embryos was different in color, texture, quantity, and organogenesis. A visible difference was found in callus texture. Callus induced on immature cotyledons was soft, while the callus induced on immature seeds and mature embryos was slightly hard in texture. More organogenic callus was achieved from mature embryos and immature seeds, as compared to the immature cotyledons. The best response was found for all

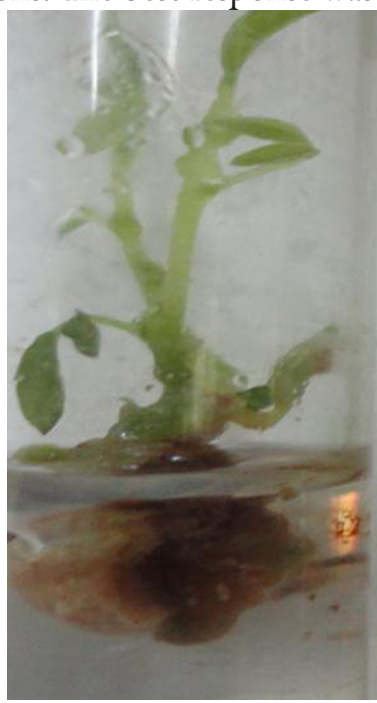

Fig. 5. Shoot induction from mature embryo callus cultured on RM1 $(1.4 \mu \mathrm{M}$ NAA and $8.88 \mu \mathrm{M} \mathrm{BA})$ 


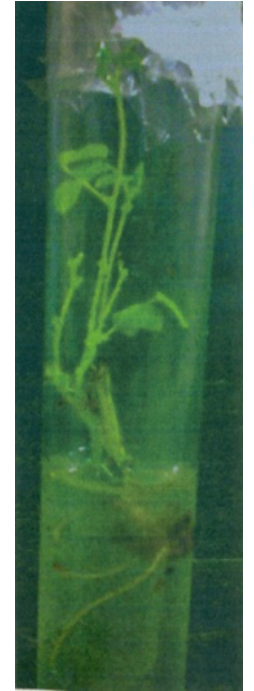

Fig. 6. Rooted shoot of Dalbergia sissoo

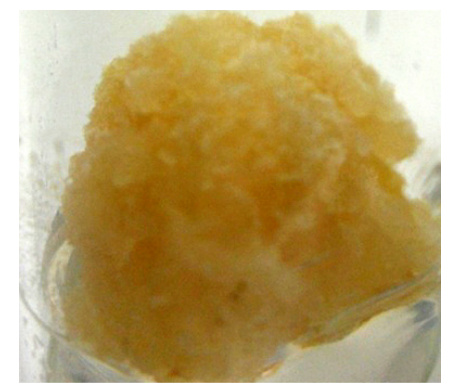

Fig. 8. Non-transformed callus of Dalbergia sissoo

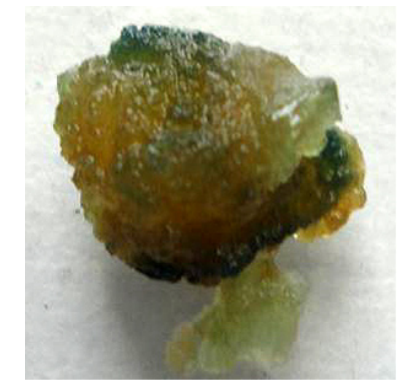

Fig. 9. Transformed callus of Dalbergia sissoo showing GUS expression (blue)

treatments for callus induction from mature embryos, and results were statistically different from immature seeds and cotyledons. To our knowledge, this was the first report that mature embryos and immature seeds were used as initial explants for in vitro regeneration of D. sissoo. Kumar et al. (1991) regenerated plants of D. sissoo from cell suspension-derived calli of D. sissoo. Callus induction occurred on cambial tissue cultured on MS medium with $9.05 \mu \mathrm{M} 2,4-\mathrm{D}$ and $0.44 \mu \mathrm{M} \mathrm{BA}$, and shoot bud differentiation occurred from cell suspensions plated on medium containing 2.22-8.88 $\mu \mathrm{M}$ BA, but without auxin. Pattnaik et al. (2000) obtained shoot organogenesis and plantlet regeneration from hypocotyl-derived cell suspension cultures of D. sissoo. Callus induction increased on MS me- dium containing $10.74 \mu \mathrm{M}$ NAA and $2.22 \mu \mathrm{M} \mathrm{BA}$, and shoot-bud differentiation was best on a medium containing $13.32 \mu \mathrm{M}$ BA and $2.69 \mu \mathrm{M}$ NAA. Singh et al. (2002) used semi-mature and mature cotyledon explants for adventitious shoot organogenesis and plant regeneration of D. sissoo. MS medium with $4.44 \mu \mathrm{M}$ BA and $0.26 \mu \mathrm{M}$ NAA was best for regeneration from semi-mature cotyledons, whereas MS medium with $22.2 \mu \mathrm{M}$ BA without NAA was best for regeneration from mature cotyledons. Chand and Singh (2005) regenerated plants from callus cultures derived from semi-mature embryos of D. sissoo. Callus was induced on MS medium with 2.26-13.57 $\mu \mathrm{M}$ 2,4-D in combination with $0.46 \mu \mathrm{M}$ and $1.16 \mu \mathrm{M}$ kinetin, and shoot regeneration occurred on MS medium containing 2.22-13.32 $\mu \mathrm{M} \mathrm{BA}$ and $1.34 \mu \mathrm{M}$ NAA. Our results indicated a better response with mature embryos as compared to immature seeds or cotyledons. Somatic embryogenesis and plantlet regeneration was achieved with $D$. sissoo using various concentrations of 2,4-D and kinetin (Das et al., 1997; Singh and Chand, 2003). Bari et al. (2008) used nodal, internodal, and shoot tip explants for callus induction and plant regeneration of $D$. sissoo. Friable green callus was induced on nodal segments cultured on MS medium with $8.88 \mu \mathrm{M} \mathrm{BA}$ and $2.69 \mu \mathrm{M} \mathrm{NAA}$, and the highest number of shoots were regenerated on MS medium containing $6.66 \mu \mathrm{M}$ BA and $2.86 \mu \mathrm{M}$ IAA. Thirunavoukkarasu et al. (2010) found MS medium to be superior to woody plant medium for micropropagation of D. sissoo. In our study, the best response for callus induction was with mature embryos cultured on MS medium with 2.71 $\mu \mathrm{M} 2,4-\mathrm{D}$ and $0.93 \mu \mathrm{M}$ kinetin, and then cultured on MS medium with $1.4 \mu \mathrm{M}$ NAA and $8.88 \mu \mathrm{M}$ BA for shoot regeneration.

Rooting microshoots of D. sissoo regenerated in vitro has been achieved using both full-strength and halfstrength MS medium containing various concentrations of IBA, IAA, NAA, or indole-3-propionic acid (IPA), or combinations thereof. Kumar et al. (1991), Pradhan et al. (1998), and Pattnaik et al. (2000) reported in vitro rooting of D. sissoo microshoots on half-strength MS medium supplemented with $5.71 \mu \mathrm{M}$ IAA, $4.92 \mu \mathrm{M}$ IBA, and 5.37 $\mu$ M NAA. Gulati and Jaiwal (1996) used a three-step process to root Sissoo microshoots regenerated from nodal cultures, by first culturing shoots on MS medium with $100 \mu \mathrm{M}$ IBA, then transfer to half-strength liquid MS medium with activated charcoal, followed by culture on half-strength liquid MS medium without plant growth regulators or charcoal. Shoots regenerated from semimature and mature cotyledons rooted on half-strength MS medium with $1.23 \mu \mathrm{M}$ and 4.92 IBA $\mu \mathrm{M}$, respectively (Singh et al., 2002). Microshoots regenerated from semimature zygotic embryos rooted on half-strength MS medium containing $1.23 \mu \mathrm{M}$ IBA (Chand and Singh, 2005). Thirunavoukkarasu et al. (2010) reported the best rooting of microshoots regenerated from nodal cultures derived from coppiced shoots was on half-strength MS medium 
146

with $7.35 \mu \mathrm{M}$ IBA. Ali et al. (2012) reported optimum rooting of $D$. sissoo microshoots on MS medium supplemented with $4.92 \mu \mathrm{M}$ IBA, whereas Joshi et al. (2003) reported rooting on half-strength MS medium with 4.92 $\mu \mathrm{M}$ IBA. In our study, the best rooting of $D$. sissoo in vitro regenerated microshoots was achieved using half-strength MS medium with $7.35 \mu \mathrm{M}$ IBA, producing on average one to three roots per shoot with a mean root length of 2.5 $\mathrm{cm}$.

In the present study, MS medium with $2.71 \mu \mathrm{M} 2,4-\mathrm{D}$ and $0.93 \mu \mathrm{M}$ kinetin (CIM1) induced callus on all three explants tested $(3.39 \pm 0.12)$. This medium was also used successfully by Chand and Singh (2004) who regenerated plants from nodal segments. Intermediate in callus induction $(2.89 \pm 0.09)$ for all explants tested was MS medium containing $8.88 \mu \mathrm{M} \mathrm{BA}$ and $2.69 \mu \mathrm{M}$ NAA (CIM2) (Chand and Singh, 2005). The least responsive was CIM3 $(1.97 \pm 0.08)$ containing $2.71 \mu \mathrm{M}$ 2,4-D and $2.69 \mu \mathrm{M}$ NAA previously studied by Sharma and Chandra (1988) and Chand and Singh (2005). In our study, mature embryos responded best compared to cotyledons and immature seeds, and shoot regeneration $(1.87 \pm 0.14)$ was best on MS medium containing $1.4 \mu \mathrm{M}$ NAA and $8.88 \mu \mathrm{M}$ BA (RM1). Chand and Singh (2005) using semi-mature zygotic embryos, found shoot regeneration from callus was best (45\%) on MS medium supplemented with $1.34 \mu \mathrm{M}$ $\mathrm{NAA}$ and 2.22-13.32 $\mu \mathrm{M} \mathrm{BA}$.

Agrobacterium- mediated transformation of woody tree species is becoming routine, especially in poplar, eucalyptus, and several pines (Bishop-Hurley et al., 2001; Cseke et al., 2007; Fillatti et al., 1987; Harcourt et al., 2000; Meilan et al., 2002). Genetic transformation of many Asian tree species still remains largely unsuccessful or unreported, and genetic transformation of D. sissoo has not been reported previously. Our preliminary results of micro-projectile bombardment of D. sissoo callus tissue showed transient GUS activity 1 week after bombardment. Although this was transient expression of a reporter gene, it provides the basis for optimizing the conditions for bombardment of $D$. sissoo in future studies for stable transformation with disease resistance genes, especially against dieback disease. Duchesne et al. (1993) reported the highest $G U S$ activity of embryogenic cell lines of Larix was in cells bombarded 5-6 d after transfer to fresh media. Aronen et al. (1994) reported transient GUS expression in 35 out of 44 tree genotypes of Pinus sylvestris (Scots pine) studied. Lambardi et al. (1998) observed high expression of GUS when 15 days subcultured embryonal-suspension tissue of Cupressus sempervirens (Mediterranean cypress) was utilized. Purohit et al. (2007) used the biolistic-mediated DNA delivery method with hypocotyls of Feronia limonia (a fruit tree) as a first step towards optimizing the parameters for stable genetic transformation. To the best of our knowledge this was the first time $D$. sissoo was shown to have transient $G U S$ expression in callus tissue via micro-projectile bombardment. Our results indicate that stable genetic transformation may be possible in the future with $D$. sissoo provided an efficient regeneration system is used.

\section{Acknowledgements}

The authors wish to acknowledge the support from Dr. Dirk Becker of the University of Hamburg, Germany for providing the $p U b i$-gus plasmid. Additionally, we thank the University of Agriculture, Faisalabad for laboratory bench space and financial support.

\section{References}

Appanah S, Allard G, Amatya SM (2000). Proceedings of the sub-regional seminar "Die-back of Sissoo (Dalbergia sissoo)", Kathmandu, Nepal, Field Document No. 18, Department of Forest Research and Survey, Ministry of Forest Research and Survey Nepal, 65 p.

Ali A, Rizwan M, Majid A, Saleem A, Naveed NH (2012). Effect of media type and explants source on micropropagation of Dalbergia sissoo: A tree of medicinal importance. J Med Plant Res 6:1742-1751.

Aronen T, Haggman H, Hohtola A (1994). Transient $\beta$-glucuronidase expression in Scots pine tissues derived from mature trees. Can J For Res 24:2006-2011.

Bakshi BK, Singh S (1967). Rusts on Indian forest trees. Indian Forest Records (Forest Pathology) 2:139-198.

Bari MA, Ferdaus KMKB, Hossain MJ (2008). Callus induction and plantlet regeneration from in vivo nodal and internodal segments and shoot tip of Dalbergia sissoo Roxb. J Bio-Sci 16:41-48

Becker D, Brettschneider R, Loerz H (1994). Fertile transgenic wheat from microprojectile bombardment of scutellar tissue. The Plant J 5:299-307.

Bishop-Hurley SL, Zabkiewicz RJ, Grace L, Gardner RC, Wagner A, Walter C (2001). Conifer genetic engineering: transgenic Pinus radiata (D. Don) and Picea abies (Karst) plants are resistant to the herbicide Buster. Plant Cell Rep 20:235-243.

Brettschneider R, Becker D, Loerz H (1997). Efficient transformation of scutellar tissue of immature maize embryos. Theor Appl Genet 94:737-748.

ChandS, Singh AK (2004). Plant regeneration from encapsulated nodal segments of Dalbergia sissoo Roxb., a timber-yielding leguminous tree species. J Plant Physiol 161:237-243.

Chand S, Singh AK (2005). Plant regeneration from semimature zygotic embryos of Dalbergia sissoo Roxb. Indian J Biotech 4:78-81.

Cseke LJ, Cseke SB, Podila GK (2007). High efficiency poplar transformation. Plant Cell Rep 26:1529-1538. Das P, Samantaray S, Roberts AV, Rout GR (1997). In vitro somatic embryogenesis of Dalbergia sissoo Roxb. - a multipurpose timber-yielding tree. Plant Cell Rep 16:578-582.

Duchesne LC, Lelu MA, Von Aderkas P, Charest PJ (1993). 
Microprojectile-mediated DNA delivery in haploid and diploid embryogenic cells of Larix spp. Can J Fores 23:312 316.

Fillatti JJ, Sellmer J, Mccown B, Haissig B, Comai L (1987). Agrobacterium mediated transformation and regeneration of Populus. Mol General Gen 206:192-199.

Gulati A, Jaiwal PK (1996). Micropropagation of Dalbergia sissoo from nodal explants of mature trees. Biol Plant 38:169175.

Harcourt RL, Kyozuka J, Floyd RB, Bateman, KS, Tanaka H, Decroocq V, Llewellyn DJ, Zhu X, Peacock WJ, Dennis ES (2000). Insect- and herbicide-resistant transgenic eucalypts. Mol Breed 6:307-315

Jefferson RA, Kavanagh TA, Bevan MW (1987). Gus fusions: $\beta$-glucuronidase as a sensitive and versatile gene fusion marker in higher plants. EMBO J 6:3901-3907.

Joshi L, Bisht P, Sharma VK, Uniyal DP (2003). Studies on effect of nutrient media for clonal propagation of superior phenotypes of Dalbergia sissoo Roxb. through tissue culture. Silvae Genetica 52:143-147.

Kumar A, Tandon P, Sharma A (1991). Morphogenetic responses of cultured cells of cambial origin of a mature tree - Dalbergia sissoo Roxb. Plant Cell Rep 9:703-706.

Lambardi M, Lachance D, Seguin A, Charest PJ (1998). Evaluation of micrprojectile-mediated DNA delivery and reporter genes for genetic transformation of the Mediterranean cypress (Cupressus sempervirens L.). Plant Cell Rep 18:198-202.

Meilan R, Auerbach DJ, Ma C, Difazio SP, Strauss SH (2002). Stability of herbicide resistance and GUS expression in transgenic hybrid poplars (Populus sp.) during four years of field trials and vegetative propagation. HortScience 37:277280.

Murashige T, Skoog FA (1962). A revised medium for rapid growth and bioassays with tobacco tissue cultures. Physiol Plant 15:473-497.

Pattnaik S, Pradhan C, Naik SK, Chand PK (2000). Shoot organogenesis and plantlet regeneration from hypocotylderived cell suspensions of a tree legume, Dalbergia sissoo Roxb. In Vitro Cell Dev Biol Plant 36:407-411.
Pradhan C, Kar S, Pattnaik S, Chand PK (1998). Propagation of Dalbergia sissoo Roxb. through in vitro shoot proliferation from cotyledonary nodes. Plant Cell Rep 18:122-126.

Purohit SD, Raghuvanshi S, Tyagi AK (2007). Biolisticmediated DNA delivery and transient expression of GUS in hypocotyls of Feronia limonia L. - A fruit tree. Indian J Biotech 6:504-507.

Rana IA, Loerz H, Schaeffer W, Becker D (2012). Over expression of chitinase and chitosanase genes from Trichoderma harzianum under constitutive and inducible promoters in order to increase disease resistance in wheat (Triticum aestivum L). Molecular Plant Breeding 3(4):3749.

Shakya DD, Lakhey PB (2007). Confirmation of Fusarium solani as the causal agent of die-back of Dalbergia sissoo in Nepal. Plant Pathol 56:1041.

Sharma S, Chandra N (1988). Organogenesis and plantlet formation in vitro in Dalbergia sissoo Roxb. J Plant Physiol 132:145-147.

Shukla AN (2008). Resistance of Dalbergia sissoo to Fusarium solani f.sp. dalbergiae. For Path 38:410-418.

Singh AK, Chand S (2003). Somatic embryogenesis and plant regeneration from cotyledon explants of a timber-yielding leguminous tree, Dalbergia sissoo Roxb. J Plant Physiol 160:415-421.

Singh AK, Chand S, Pattnaik S, Chand PK (2002). Adventitious shoot organogenesis and plant regeneration from cotyledons of Dalbergia sissoo Roxb., a timber yielding tree legume. Plant Cell Tiss Org Cult 68:203-209.

Steel RGD, Torrie JH (1980). Principles and procedures of statistics. McGraw-Hill Book Co., New York.

Suwal B, Karki A, Rajbihandary SB (1988). The in vitro proliferation of forest trees 1. Dalbergia sissoo Roxb. ex Dc. Silvae Genetica 37:26-28.

Thirunavoukkarasu M, Panda PK, Nayak P, Behera PR, Satpathy GB (2010). Effect of media type and explant source on micropropagation of Dalbergia Sissoo Roxb. - An important multipurpose forest tree. Intl Res J Plant Sci 1:155-162. 